\title{
Extraction of Rare Earth and Heavy Metals, Using lonic Solvents as Extraction Medium (A Review)
}

\author{
DIDIER VILLEMIN ${ }^{1}$ and MOHAMED AMINE DIDI²* \\ 'Laboratoire de Chimie Moléculaire et Thioorganique, UMR CNRS 6507, \\ INC3M, FR 3038, Labex EMC3, ENSICAEN, 14050 Caen, France. \\ 'Laboratory of Separation and Purification Technology, Tlemcen University, \\ Faculty of Sciences, Department of Chemistry,Box 119, Algeria. \\ http://dx.doi.org/10.13005/ojc/290402
}

(Received: September 04, 2013; Accepted: October 25, 2013)

\begin{abstract}
A review. In this paper, separation of metals with solvent extraction, ionic liquid extraction phase and chelate extraction of metal ion were reviewed.
\end{abstract}

Key words: Ionic liquid; Solvent extraction; Metals; chelate, Rare earth metals.

\section{INTRODUCTION}

Ionic liquids show unique properties such as nonvolatility (negligible vapor pressure), thermal stability, nonflammable nature, lower reactivity, strong ability to dissolve a large variety of organic and inorganic compounds... That's why we should study the potential of it to the extraction of rare earth (lanthanides plus Sc and $\mathrm{Y}$ ) and heavy metals. Indeed, heavy metals are a big problem for industrial companies who want to recycle the waste like mercury or cadmium to be more economically profitable as well as for the environment. There is a much bigger application. In fact, the extraction of rare earth metals is becoming more and more important due to the fact that it's everywhere in technological devices like cellphones, television, computers, tablet, permanent magnets... So, we need to find a way to recycle it (to extract it) because China is almost the only supplier with more than $95 \%$ of the worldwide production of rare earth metals and they have decided to limit the exportation forcing people to increase the price of raw materials. ${ }^{[1]}$

In this report, we will study the different extractions techniques of rare earth metals and after the ones for heavy metals.

\section{Extraction of rare earth metals}

Different techniques are used to extract rare earth metals (REM) and the number of publications regarding this topic is increasing. In this part, we will focus on the extraction using extractants and another part using coordinated anions in the ionic liquid. 


\section{RTILs}

Room-temperature ionic liquids RTILs are the first ionic liquids used to extract metals from aqueous solutions. They've become the base for most of the new ILs made after. Those ILs are made

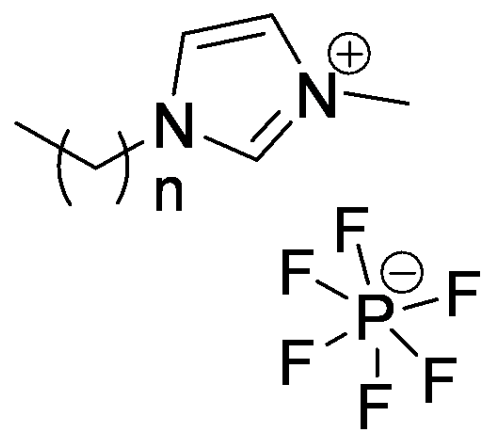

with imidazolium salts combined with different anions like $\mathrm{PF}_{6}^{-}$or $\mathrm{NTf}_{2}$. They are noted [C $\mathrm{C}_{n} \mathrm{MIM}$ ] with $n$ equal to the number of carbon for the alkyl chain on the imidazole (Figure 1).<smiles>C[n+]1ccn(C2CC2(C)C)c1</smiles><smiles>O=S(=O)(NS(=O)(=O)C(F)(F)F)C(F)(F)F</smiles>

Fig. 1: $\left[\mathrm{C}_{n} \mathrm{MIM}\right]\left[\mathrm{PF}_{6}\right]$ and $\left[\mathrm{C}_{\mathrm{n}} \mathrm{MIM}\right]\left[\mathrm{NTf}_{2}\right]$

This was the first potential ILs to be used for extraction but their problem is that the solubility of the lanthanides in it is really poor. A lot of examples are present in literature; one of them is the study made by Zuo et al in which they studied the potential of those RTIL to separate Cerium from aqueous solution containing thorium and lanthanides. ${ }^{[2]}$

The results showed quite good results for Cerium but when other lanthanides were tried, the results weren't good enough. This study proves the need of the IL to have an extractant to facilitate the extraction.

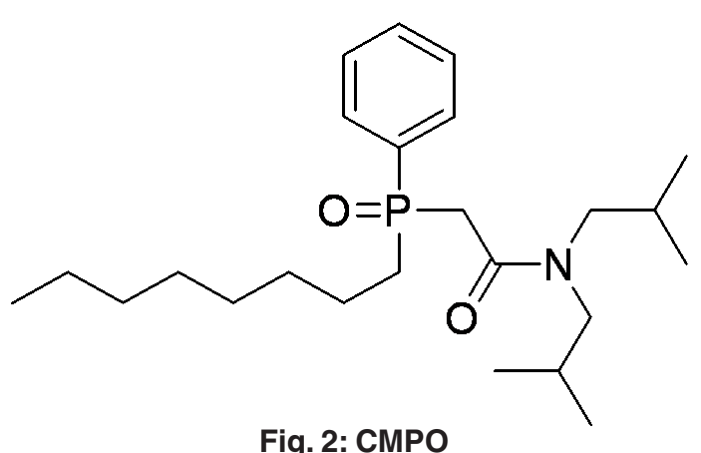

Three rare earth metals are studied $\mathrm{Ce}^{3+}$, $\mathrm{Eu}^{3+}$ and $\mathrm{Y}^{3+}$ with an increasing concentration of CMPO (black symbols) in comparison to the same extraction but in dodecane. They prove that the

\section{Extraction with extractants First method}

Charged metal ions are usually insoluble in hydrophobic ionic liquids (IL), so extractants are necessary in the IL's phase just as in organic solvent. First workswere about the use of CMPO: Octyl(phenyl)-N,N-diisobutyl carbamoylmethyl phosphine oxide(Figure 2). ${ }^{[3]}$

As CMPO is a neutral extractants, an anion (such as $\mathrm{NO}_{3}^{-}$) is required in acidic conditions to extract the cationic metal ions. The IL used was [BMIM][PF ${ }_{6}$ (Figure 3).

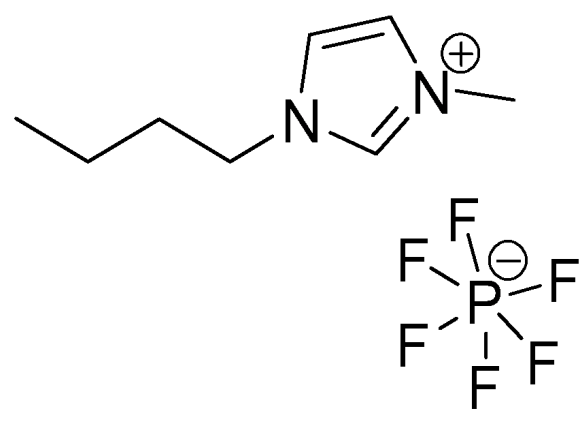

Fig. 3: [BMIM] $\left[\mathrm{PF}_{6}\right]$

extractability of CMPO is highly better in IL than in a classic organic solvent (the volume of needed extractant is divided by 17). 
The main problem with this kind of process was that after the metals comes to the IL phase, the extraction of it was hard due to the mechanism in the IL system. Indeed, the extraction involves cation exchange between the IL and aqueous phase, and the $\mathrm{IL}$ anions in the extracting phase which act as the counter anions of the extracted phase.
The AHA, DTPA, EDTA and citric acid have been chosen because it's known that they form water-soluble complex with many metal ions. The optimum solution is the number 5 . This was the first accomplished stripping of lanthanides in literature.

Table 1: The different extractants used

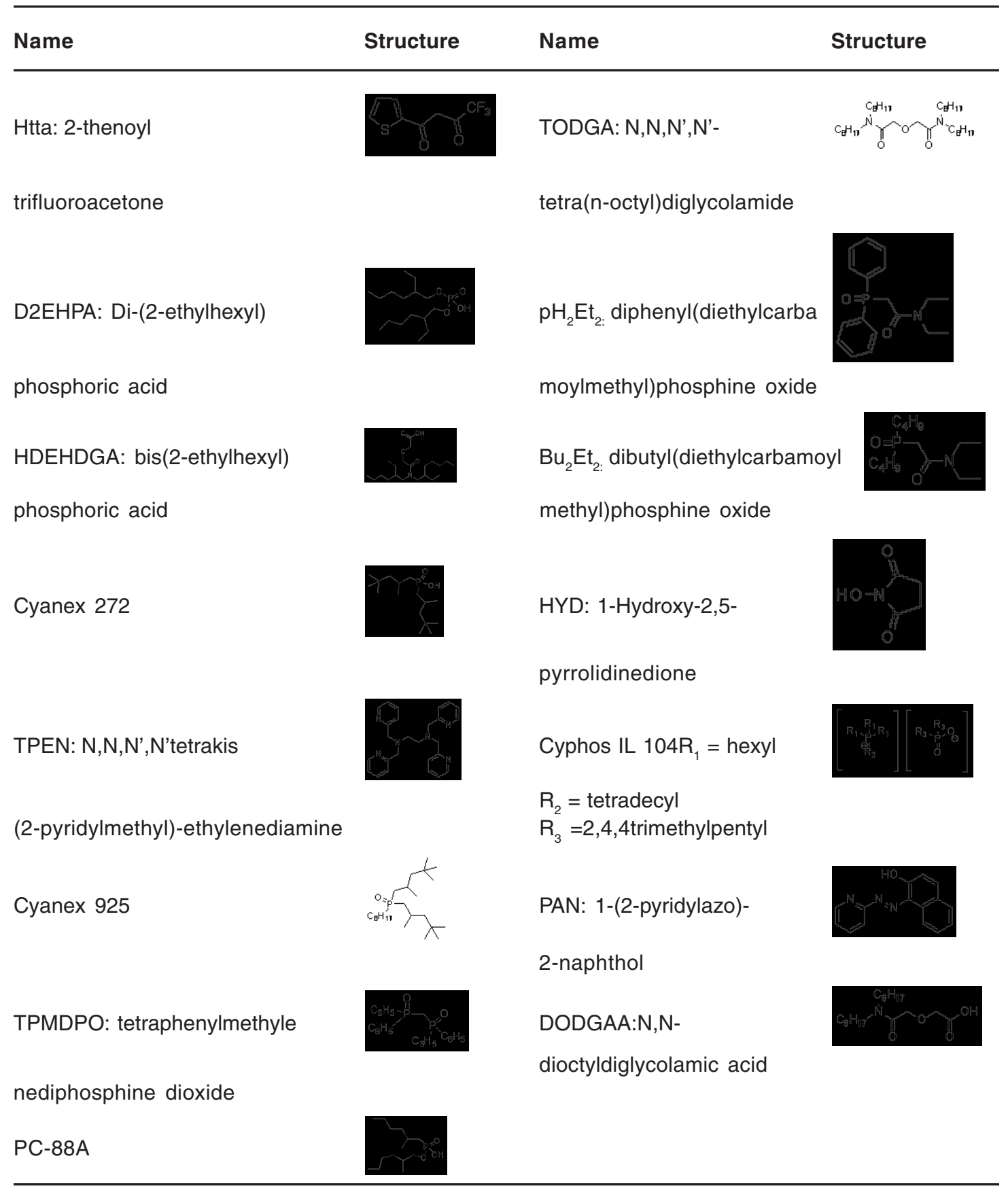




\section{Improvements}

Recently, others extractants were studied to extract specific lanthanides to improve this difficulty. ${ }^{[4]}$ Some reviews already explained the role and the consequences of the addition of the extractants. ${ }^{[5]}$ The different extractants are listed in the Table 1:

The use of Htta was studied by Jensen et al in 2003. ${ }^{[6]}$ With that goal, they studied trivalent lanthanides $\mathrm{Ln}^{3+}$ with Htta in RTILs [C $\left.\mathrm{C}_{4} \mathrm{MIM}\right]\left[\mathrm{NTf}_{2}\right]$. The big advantage of this extractant is the facility to strip the metal ion from the IL after the extraction. This was the first time the recovering of the metal ions was efficient in the literature.

\section{D2EHPA}

The first reproducible study was made by Yoon et al in 2010 as an extractant in RTILs $\left[\mathrm{C}_{4} \mathrm{MIM}\right]\left[\mathrm{PF}_{6}\right] \cdot{ }^{[7]}$ Five different lanthanides elements were studied in their chloride form: $\mathrm{CeCl}_{3}, \mathrm{NdCl}_{3}$, $\mathrm{SmCl}_{3}, \mathrm{DyCl}_{3}$ and $\mathrm{YbCl}_{3}$. It was proved that the extractability of lanthanides increases as the ionic radius of the lanthanides decreases.

Moreover, a quite little quantity of D2EHPA is needed to have a good extraction making this process not expensive.

\section{D2EHPA- HDEHDGA}

A comparison of those two extractants has been made by Rout et al in 2011 particularly on Americium and Europium ${ }^{8-9}$. This study showed extraordinary power of extraction for these metals in RTIL like [OMIMㄹ][ $\mathrm{NTf}_{2}$ ].

This study revealed that there is an optimum $\mathrm{pH}$ but also that HDEHDGA is superior in terms of extractability of metals than D2EHPA. D2EHPA was before studied with other organophosphorus extractants but with those results, the tendency would be to use derivatives of HDEHDGA.

\section{D2EHPA $-\mathrm{C}_{4}$ mim}

A novel room temperature ionic liquid (2butyl-imidazolium di-(2-ethylhexyl) phosphate) ([C $\operatorname{mim}][$ D2EHPA], figure 4) was synthesized and tested as extractant in the mercury (II) liquid-liquid extraction.
The effects of parameters such as aqueous to organic phase's volume ratio, metal concentration IL concentration, $\mathrm{pH}$ levels, ionic strength, and temperature were reported ${ }^{10}$.
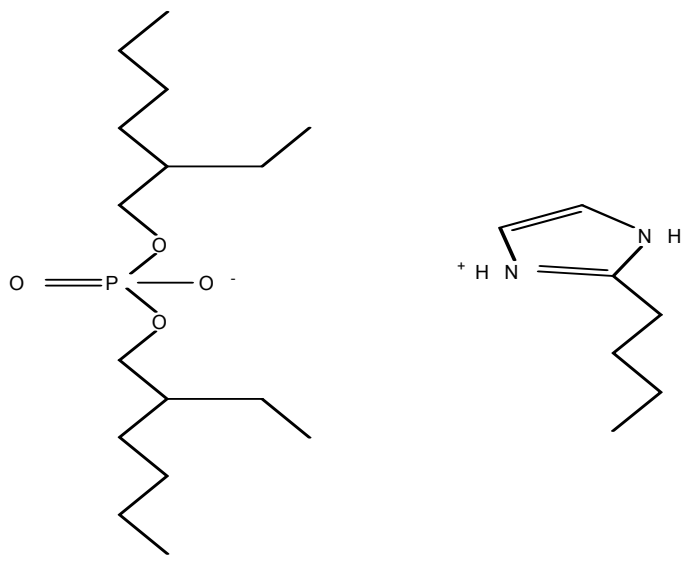

Figure 4: Structure of 2-butyl-imidazolium bis(2-ethylhexyl) phosphate

\section{PC-88A}

Continuously with the previous extractants, PC-88A (commercially available) was study as another organophosphorus extractant in RTILs $\left[\mathrm{C}_{n} \mathrm{MIMI}\right]\left[\mathrm{Tf}_{2} \mathrm{~N}\right](\mathrm{n}=2,4,8,12) .{ }^{[11]}$ It appeared that higher extraction efficiency was given by $\left[\mathrm{C}_{8} \mathrm{MIM}\right]$.

However, the stripping was easier with $\left[\mathrm{C}_{12} \mathrm{MIM}\right]$ thanks to $\mathrm{HNO}_{3}$.

The extractability of the metal is controlled by $\mathrm{pH}$ of the aqueous phase. Indeed, in function of the metal, the $\mathrm{pH}$ is not the same. This property was evaluated by the $\mathrm{pH}_{0.5}$ corresponding to the $\mathrm{pH}$ needed to extract $50 \%$ of the metal.

The problem with that extractant is the poor solubility of it in the IL.

\section{TPEN}

TPEN4 is a neutral hexadentate ligand effectively coordinating with lanthanides. It's soluble in ILs due to the high affinity of the pyridyl groups for the ILs and showed high extraction efficiency for lanthanides. 


\section{Cyanex 925}

This extractant was used by Sun et a/ with the goal to separate Scandium from Yttrium and other lanthanides ${ }^{12}$. This extractant was first mixed with $\mathrm{A} 336^{3}$ as cation and $\mathrm{NO}_{3}$ as the anion. The only result of this study is the potential of Cyanex 925 to separate Scandium from Yttrium whereas for the other lanthanides, this extractant is not sufficient enough.

\section{Cyphos IL 104}

This extractant was used in RTIL $\left[\mathrm{C}_{8} \mathrm{MIM}\right]\left[\mathrm{PF}_{6}\right]^{13}$. The final IL was synthesized by a $\mathrm{sol} / \mathrm{gel}$ method. The name of this new IL is B104SG. This extractant showed incredible results compared to the previous one Cyanex 925 (noted IL923SG). With those results, this extractant needs to be more studied in the future.

\section{HYD}

This was first studied by Mallah et al and more recently by Jamali and al. ${ }^{14-15}$. The difference between the two publications is the presence of PAN in the mixture to ameliorate the extractability of lanthanides with HYD. But this extractant didn't prove real property to extract lanthanides but just to create IL which can be used after in a DLLME: Dispersive liquid-liquid micro-extraction.

\section{DODGAA and TODGA}

Those extractants are members of the same family and have similar properties. TODGAA was the first to be studied4it has high affinity for lanthanides in RTIL systems. Its extraction ability was strongly demonstrated although the selectivity in the lanthanide series was different.

However, the stripping and the recovery of the TODGA were not sufficient enough. That's why its analog, DODGAA, was studied ${ }^{16}$. It has a molecular structure in which one of the two carbamoyl groups in TODGA is replaced by a carboxyl group. It is soluble in RTIL and has high affinity for rare earth metals. They try different RTIL to evaluate the potential of DODGAA ([C $\left.\mathrm{C}_{n} \mathrm{MIM}\right], n=4$, $8,12)$.

This study shows two important things:

The high extractability for lanthanides

The poor one for $\mathrm{Zn}$.
This phenomenon can be explained by the tridentate diglycolamic acid trapping the metal with big radius. Moreover, high extraction performance was observed for the metal ions when ILs having shorter alkyl chains in the imidazolium cation.

Finally strippingwas easily accomplished with an acid solution in poor proportions such as nitric acid and the IL is after then reusable.

Another study has the same results as this one. ${ }^{[17]}$ Indeed, they evaluate the extractability of the whole series of lanthanides and showed the $\mathrm{pH}_{0.5}$ too for different sizes of alkyl chain.

All the rare earth elements could be extracted at low $\mathrm{pH}$, but like the previous analysis, the optimum conditions needs to be defined before the use of such a system.

Finally, the stripping of those elements was successfully demonstrated by Baba et alshowing once again that for transition metals, this extractant isn't good whereas for lanthanides, the extraction and the recovery is quite good. ${ }^{[18]}$

This extractant is a promising one to the recovery of rare earth metals in waste solutions. Recently, this extractant has been used to form membranes to ameliorate the extraction processes.

\section{The others}

Some of others extractants mentioned earlier have been studied such as Cyanex 272, TPMDPO added with $\mathrm{Ph}_{2} \mathrm{Et}_{2}$ or $\mathrm{Bu}_{2} \mathrm{Et}_{2}$. But they're still not sufficient enough to be interesting in the recycling of rare earth metals from waste. ${ }^{[19]}$

\section{Extractions using ionic liquids with coordinated anions}

The main problem of ionic liquids with weakly coordinated anions is that the metal salts are poorly soluble in them. A solution to this problem is to attach functional groups to the cationic core. That's what Nockemann et al studied in a recent publication $^{20}$. They showed that hydrophobic ionic liquids can be obtained by using the hexafluoroacetylacetonate anion [hfac]. In this study, cations are imidazolium salts and several member 
of this family have been studied: [ $\mathrm{C}_{\mathrm{x}} \mathrm{min}$ ] $(x=2,4,6,8,10,16,18)$ represented in the Figure 5.
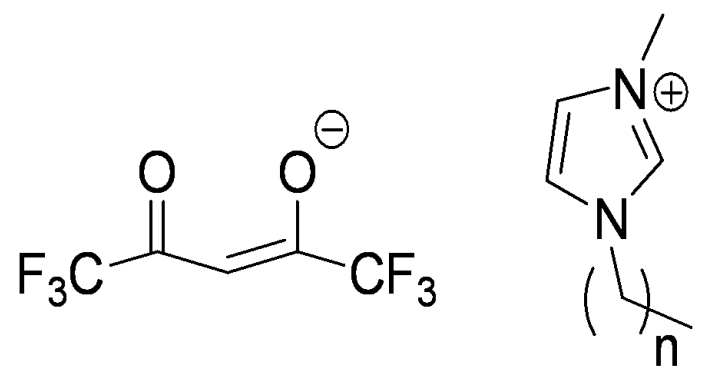

Fig. 5: $\left[C_{n} \operatorname{mim}\right][h f a c]$

Those ionic liquids were prepared y a methathesis between an organic chloride salt and ammonium hexafluoroacetylacetonate in acetonitrile. The precipitate was filtered and the acetonitrille solvent was removed under reduced pressure. The residue was then redissolved in dichloromethane and washed with water and reevaporated to obtain the pure ionic liquid. It is noticeable that the ionic liquid is better when the alkyl chain is a butyl or even longer to reinforce the hydrophobicity.

This study, based on neodymium, cobalt and copper, showed excellent results to extract metals. An aqueous solution of neodymium salt was poured on top of a sample of the ionic liquid $\left[\mathrm{C}_{4} \mathrm{~min}\right][\mathrm{hfac}]$ (with a butyl chain because it was the most hydrophobic compound). This extraction process occurred at the interface between the two liquid phases without stirring.

Instantaneously after the addition of neodymium, the ionic liquid changes color explaining by the fact that there is a transfer of $\mathrm{Nd}^{3+}$ between the two phases. The final step of this extraction is the formation of a complex $\left[\mathrm{Nd}(\mathrm{hfac})_{4}\right]$ in the ionic liquid phase. A crystal structure of this complexe was made showing that the neodymium is surrounded by four bidentately coordinating diketone anions in a quadratic antiprismatic geometry.

The acidic hydrogen atom forms hydrogen bond with the oxygen making this complex even more stable. That's why this process is so efficient.

Another study was made by Binnemans et al showing an improvement into solubilizing lanthanides into ionic liquids which is the main problem with lanthanides and ionic liquids. ${ }^{[23]}$ With that intention, the synthesis of $\left[\mathrm{Ln}(\mathrm{NCS})_{4}\left(\mathrm{H}_{2} \mathrm{O}\right)_{y}\right]^{3-x}$ $(x=6-8, y=0-2)$ was made by a metathesis procedure starting from stoichiometric amounts of lanthanides(III) perchlorate, ammonium thiocyanate, and thiocyanate ionic liquid with the corresponding imidazolium salt. The thiocyanate was introduced to ameliorate the solubilization of the lanthanide into the ionic liquid.

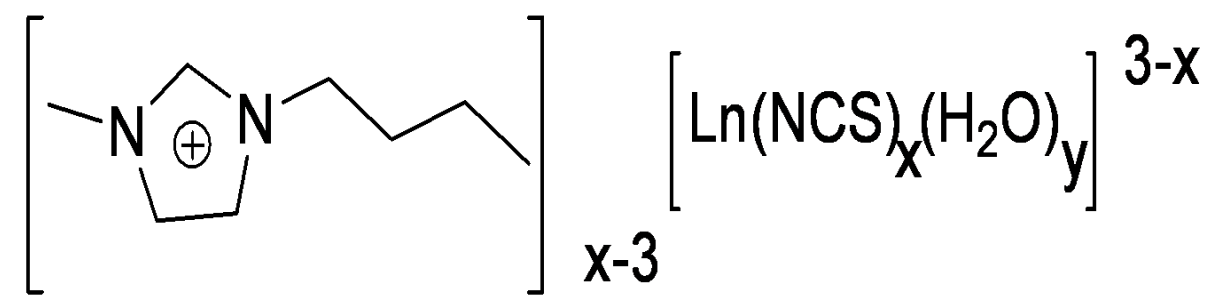

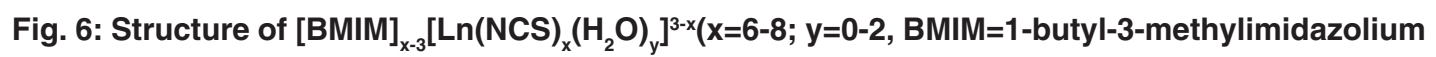

This study showed great results and almost all lanthanides was extracted by this process by the creation of a new ionic liquid. The main problem of this process is that the ionic liquid is not regenerate at the end of the process.

The second view of extracting rare earth metals with extractants are the phosphine oxide functionalized imidazolium. That's what Vicente et al studied in 2012. ${ }^{[21]}$

According to Scheme 1, they synthesized those ILs in two steps, using alkyl bromidefunctionalized 1,2 dimethyl-imidazolium ionic liquid with $\left[\mathrm{Tf}_{2}\right]^{-}$and potassium diphosphine. The resulting phosphine is oxidized by hydrogen peroxide to give the desired [DMImC $\left.{ }_{n} \mathrm{P}(\mathrm{O}) \mathrm{Ph}_{2}\right]\left[\mathrm{NTf}_{2}\right]$. 


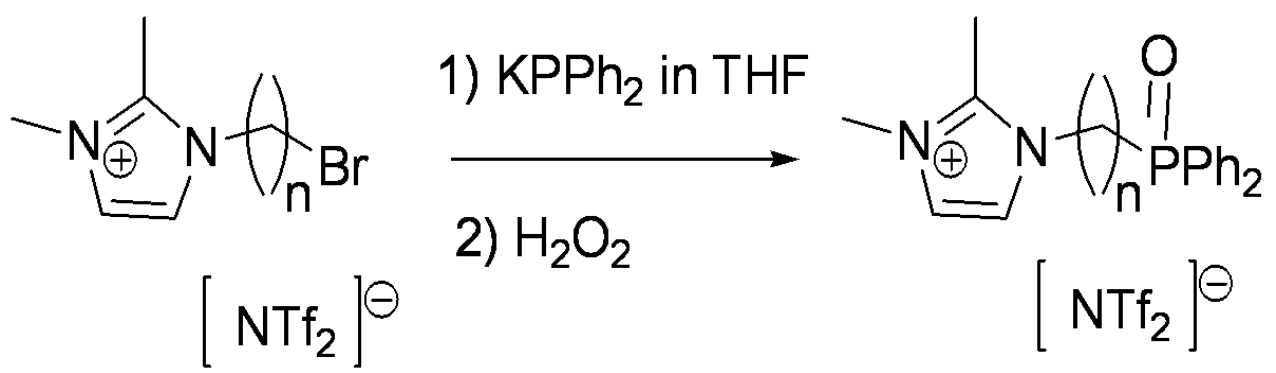

Scheme 1

When this new IL is in contact with a solution of $\mathrm{Eu}(\mathrm{hfac})_{3} \cdot 6 \mathrm{H}_{2} \mathrm{O}$, there is the formation of crystal which is the complex of Eu(hfac) $\left(\mathrm{DMImC}_{\mathrm{n}} \mathrm{P}(\mathrm{O}) \mathrm{Ph}_{2}\right)$. The structure of this complex is shown on Figure 7. It surprisingly indicates that those new ILs have the ability to be tuneable for lanthanides.

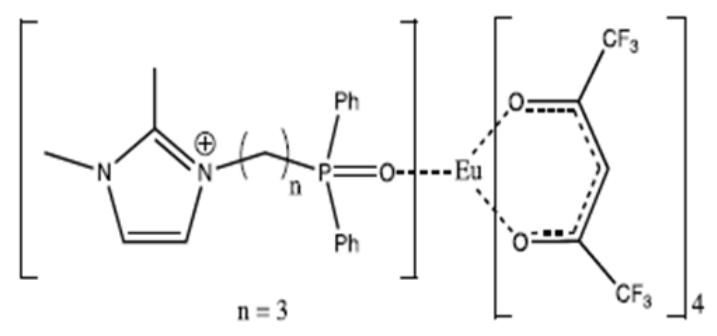

Fig. 7: structure of the Europium complex
This property shows the potential of these new ILs in the extraction process of lanthanides, actinides or transition metals.

Finally, Nockemann et al are studying the extraction of lanthanides using trihexyltetradecyl phosphonium $\left[\mathrm{P}_{666(14)}\right]^{+}$(Figure 11) as cation to trap lanthanides by making new ionic liquids containing lanthanides, allowing it to extract the metal from water. ${ }^{[22]}$

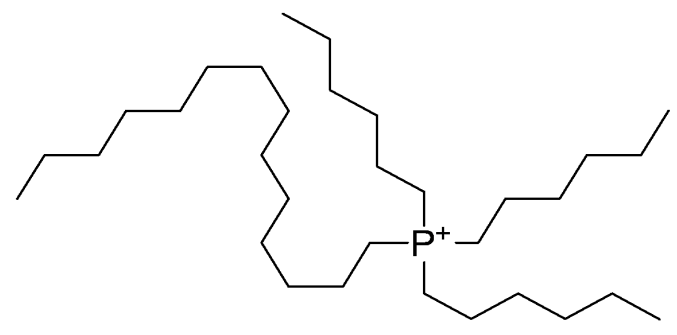

Fig. 8: $\left[P_{666(14)}\right]^{+}$

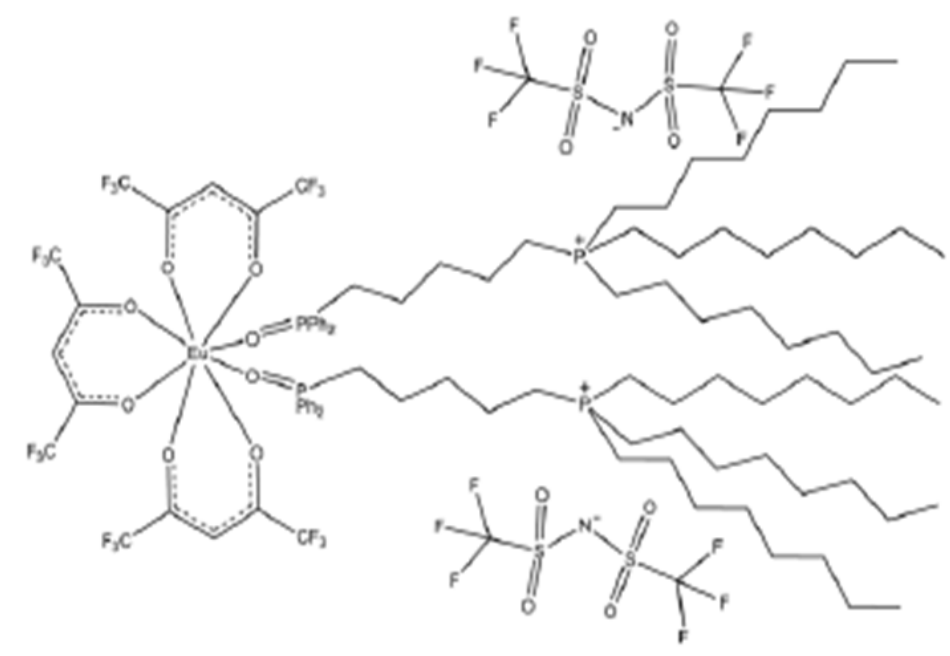

Fig. 9: Structure of the new IL composed with $\left[\mathrm{P}_{666(14)}\right]^{+}$ 
They studied a lot of lanthanides. But the major application of this is not the extraction of lanthanides but the realization of OLED materials for futures screens.

The structure of the final IL created is in the Figure 9. As we can see, this is the evolution of the previous Europium complex.

\section{Task specifics ionic liquids}

Task-Specific lonic Liquids (TSIL) are ionic liquids with functional group covalently tethered to the cationic or anionic part. When the functional group has the ability to coordinate to the metal ion (preferably as a bidentate or a polydentate liguand), it is easier to dissolve metal oxides or metal salts into the ionic liquids. The major drawback of these TSIL is that they are often only accessible after multistep synthetic procedure. In a search for cheap and easily accessible cationic building blocks for ionic liquid alternatives, Binnemans et al tried to make TSIL with betaine. ${ }^{[23]}$ Betaine is the trivial name for 1-carboxy- $\mathrm{N}, \mathrm{N}, \mathrm{N}$-trimethylmethanaminium. (Figure 10).

ith that intention, they introduced protonated betaine with bis(trifluoromethysulfonyl) imide, [Hbet][Tf $\left.{ }_{2} \mathrm{~N}\right]$, as a potential new TSIL for selective solubilization of metal oxides and metal salts (Figure 11).

The solubility of different metal oxides and metal salts has been studied. It appeared that this kind of TSIL is sensible of temperature and $\mathrm{pH}$. Indeed, [Hbet][ $\left.\mathrm{Tf}_{2} \mathrm{~N}\right]$ forms a two phases system with water at room temperature and slightly above but when it's hotter, it's a one-phase mixture.

This is the same problem with the $\mathrm{pH}$. Indeed, when the $\mathrm{pH}$ is around 8 , the TSIL and the water form a one-phase mixture whereas it's a twophase mixtures when the $\mathrm{pH}$ is equal to 1.5 . This property shows the obligation to work in an acidic solution to extract metal oxides.

When those properties are established, it's interesting to study the ability of $[\mathrm{Hbet}]\left[\mathrm{Tf}_{2} \mathrm{~N}\right]$ to dissolve metal oxide. So, Binnemans et al, demonstrated that this system is able to dissolve the following oxides: $\mathrm{Sc}_{2} \mathrm{O}_{3}, \mathrm{Y}_{2} \mathrm{O}_{3}, \mathrm{La}_{2} \mathrm{O}_{3}, \operatorname{Pr}_{6} \mathrm{O}_{11}$,

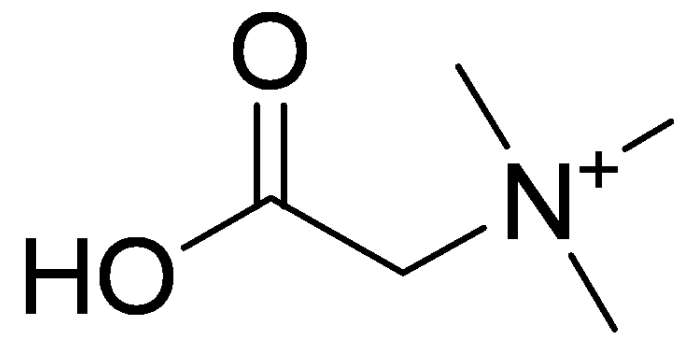

Fig. 10: Betaine

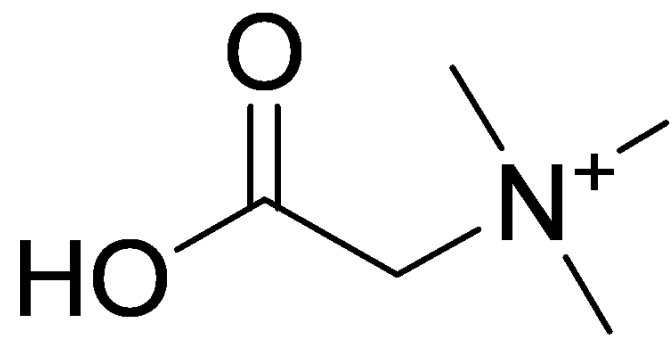

Fig. 11: [Hbet][Tf $\left.{ }_{2} \mathrm{~N}\right]$

$\mathrm{Nd}_{2} \mathrm{O}_{3}, \mathrm{Sm}_{2} \mathrm{O}_{3}, \mathrm{Eu}_{2} \mathrm{O}_{3}, \mathrm{Gd}_{2} \mathrm{O}_{3}, \mathrm{~Tb}_{4} \mathrm{O}_{7}, \mathrm{Dy}_{2} \mathrm{O}_{8}, \mathrm{Ho}_{2} \mathrm{O}_{3}$, $\mathrm{Er}_{2} \mathrm{O}_{3}, \mathrm{Tm}_{2} \mathrm{O}_{3}, \mathrm{Yb}_{2} \mathrm{O}_{3}, \mathrm{Lu}_{2} \mathrm{O}_{3}, \mathrm{UO}_{3}, \mathrm{PbO}, \mathrm{ZnO}, \mathrm{CdO}$, $\mathrm{HgO}, \mathrm{CuO}, \mathrm{Ag}_{2} \mathrm{O}, \mathrm{NiO}, \mathrm{PdO}$ and $\mathrm{MnO} \cdot{ }^{[22]}$ The metal oxide is mixed with $\left.[\mathrm{Hbet}] \mathrm{Tf}_{2} \mathrm{~N}\right]$ and water and it's stirred at room temperature for several hours. It appeared that not all metal oxides were soubilized in [Hbet][Tf $\left.{ }_{2} \mathrm{~N}\right]$. Insoluble or very poorly soluble are iron, manganese and cobalt oxides as well as aluminum and silicon oxides. This property can be explain by the fact that the metal oxide reacts with the carboxylic acid group of the ionic liquid to form a carboxylate complex into water.

Then, the metal can be stripped from betaine by extracting the ionic liquid by an acidic aqueous solution of diluted hydrochloride or diluted nitric acid. The metal complex of protonated betaine is decomposed and the betaine ionic liquid is regenerated. The ratio of the metal content in the aqueous phase to the ionic liquid phase is $1: 82$ after the first extraction. After a second one, almost all the metal is extracted.

$[\mathrm{Hbet}]\left[\mathrm{Tf}_{2} \mathrm{~N}\right]$ can be formed towards several synthetic routes. The main one is by reaction of the zwitterionic betaine with the acid hydrogen and 
$\mathrm{Tf}_{2} \mathrm{NH}$. This reaction involves a simple proton transfer from the bis(trifluoromethylsulfonyl)imide to the more basic carboxylate group, so that the betaine will be protonated. This is a general method, applicable for the preparation of other betaine salts.

\section{Extraction of heavy metals}

Heavy metals are big challenges in industry because of the wastes produced by the fabrication of various products. Those wastes are a problem for environment: we need to extract them to reuse it. In this part, we will study different ways to accomplish that.

RTILs

The room-temperature ionic liquids, RTILs, are formed by imidazolium salts with alkyl chain. This is the same process that for the rare

Table 2: Ion percentage of $\mathrm{Hg}^{2+}$ at $60^{\circ} \mathrm{C}$ as a function of time

\begin{tabular}{|c|c|c|c|}
\hline \multirow{2}{*}{$\begin{array}{l}\text { Time } \\
\text { (h) }\end{array}$} & \multicolumn{3}{|c|}{$\% \mathrm{Hg}$ (II) in IL } \\
\hline & {$\left[\mathrm{C}_{4} \mathrm{MIM}\right]$} & [C ${ }_{6}$ MIM] & $\left.\mathrm{C}_{8} \mathrm{MIM}\right]\left[\mathrm{PF}_{6}\right]$ \\
\hline 4 & 70 & 62 & 90 \\
\hline 6 & 79 & 76 & 94 \\
\hline 8 & 86 & 82 & 97 \\
\hline 12 & 97 & 97 & 100 \\
\hline 24 & 98 & 100 & - \\
\hline 30 & 100 & - & - \\
\hline
\end{tabular}

earth metals. The major products are made with BMIM or CMIM. The question was the influence of the alkyl chain on the extraction process. With that intention, Germani et al studied the effects of the alkyl chain on ILs composed of $\mathrm{C}_{\mathrm{n}}$ MIM (Figure 12) for the extraction of mercury. ${ }^{[24]}$

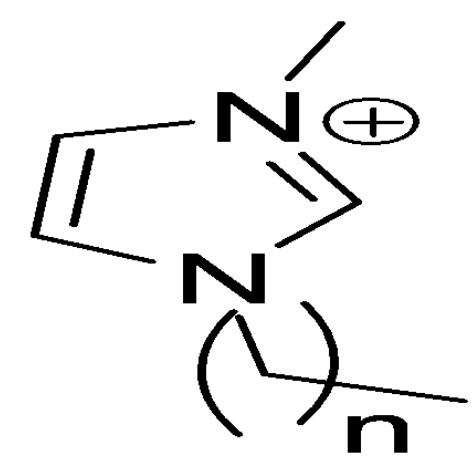

Fig. 12: $\left[C_{n} M I M\right], n=4,6,8$

Mercury was chosen because of its facility to be extracted by that kind of IL. This study showed that longer the chain is, better the extraction is (Table 2).

The second parameter studied was the temperature. Indeed, they showed that lower the temperature is, higher the time of extraction is (Figure 13).

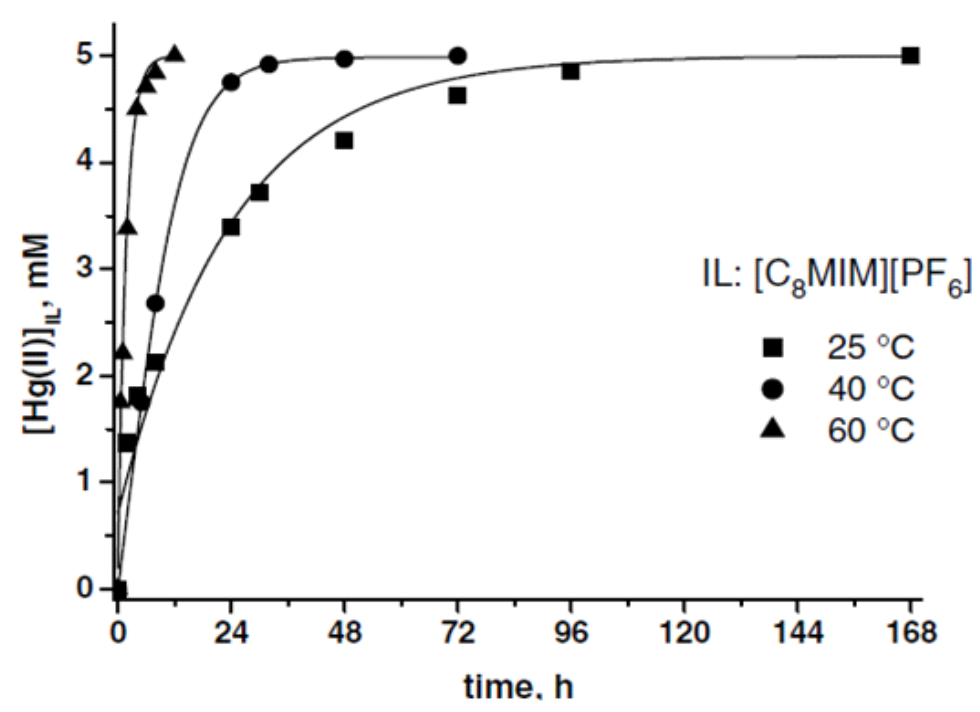

Fig. 13: Extractability of $\mathrm{Hg}$ as function of the temperature 
So, to have better conditions for that kind of extraction, we need to have long alkyl chain like octyl and temperature around $60^{\circ} \mathrm{C}$.

\section{Coordinated anions:}

This is the same process as earlier, with rare earth metals. ${ }^{[24]}$ After the reaction at the interface between $\left[\mathrm{C}_{4} \mathrm{~min}\right][\mathrm{hfac}]$ and a solution of Cobalt, two phases are observed and a change of color for the ionic liquid instantaneously after the addition of the cobalt complex.

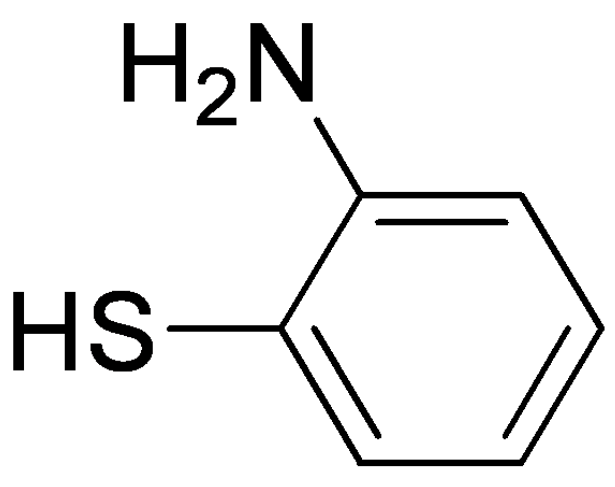

Fig. 14: 2-aminothiophenol

This addition of extractant improves the extraction percentage of $\mathrm{Ni}, \mathrm{Cu}$ and $\mathrm{Pb}$ (Table 3: Values of Extraction).

The percentage of $\mathrm{Pb}$ is still low but this is the best actually. After the extraction I the ionic liquid, we need to strip the metal from the IL. It was proved that with the addition of nitric acid, the stripping level is high.

Table 3: Values of Extraction

\begin{tabular}{lc}
\hline Metal ion & $\% \mathrm{E}$ \\
\hline $\mathrm{Ni}^{2+}$ & 57 \\
$\mathrm{~Pb}^{2+}$ & 20 \\
$\mathrm{Cu}^{2+}$ & 76 \\
\hline
\end{tabular}

Dithiozone

Dithiozone (Figure 16) are sulphur compounds used by Chen et alto improve extraction
A crystal structure was also made, showing that the cobalt(II) ion is octahedrally surrounded by three hexafluoroacetylacetonate anions.

\section{Addition of extractant}

2-aminothiophenol

An improvement of the previous works has been made by Lerlapwasin et al added the 2aminothiophenol as an extractant into a RTIL 1butyl-3-methylimidazolium hexafluorophosphate [BMIM][PF ${ }_{6}$ ]( Figure 14:2-aminothiophenol;Figure 15:[BMIM] [PF $\left.{ }_{6}\right]^{[25]}$

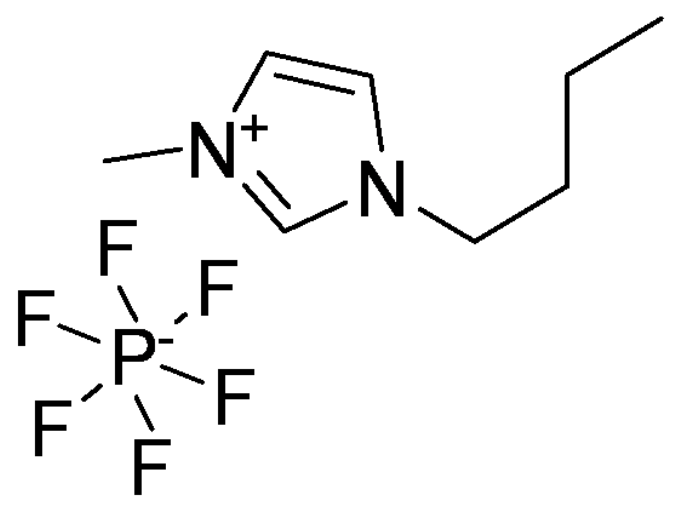

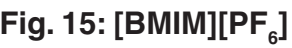

of metals in RTIL composed with imidazolium salts. ${ }^{[26-27]}$<smiles>S=C(N=Nc1ccccc1)NNc1ccccc1</smiles>

Fig. 16: Dithiozone

This study is surprising in the sense that all others publications showed that the acidic $\mathrm{pH}$ is important but in this one, a basic $\mathrm{pH}$ is better to extract.

This process is proved to be reproducible and efficient towards some metals. Besides, the IL can be used again by stripping the metal from the IL by nitric acid. 


\section{Aza-Crown ether}

This extractants have been studied by Huimin et al. ${ }^{[28]}$ The structures are based on crown ether but with a nitrogen atom in the ring. The best results were obtained with N-Dodecyl Aza-18crown-6 (Figure 17).

In way to study the extractability of some metals $\left(\mathrm{Sr}^{2+}, \mathrm{K}^{+}, \mathrm{Cs}^{+}, \mathrm{Na}^{+}\right)$, the aza crown-ether was added in four different RTIL based on imidazolium salts $\left[\mathrm{C}_{n} \mathrm{MIM}\right]\left[\mathrm{NTf}_{2}\right](\mathrm{n}=2,4,6,8)$. This study revealed the high power of aza crown-ether to extract particularly strontium.

Those results prove that the best extraction process is the addition of the aza crown-ether with an imidazolium salt composed with an alkyl chain of two or four atoms.

The problem with that process is the price of the extractant. That's why they also studied the recycling of it. With a simple stripping of the metal with the addition of an aqueous phase containing nitric acid, the recovery of the metal is excellent which allows this process to be reproducible and profitable.

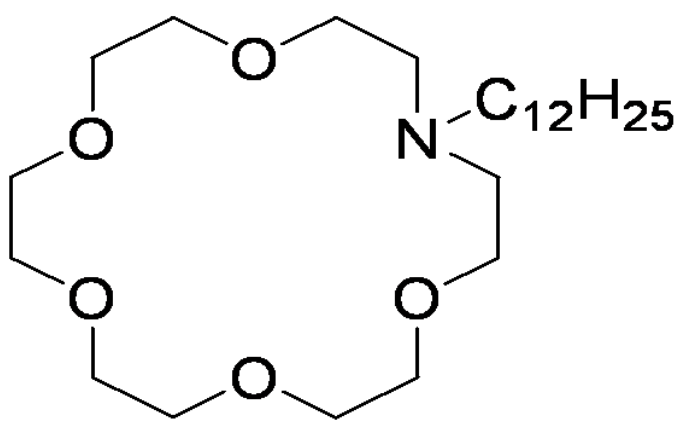

Fig. 17: N-Dodecyl Aza-18-crown-6

These observations demonstrate that the extraction system based on $\mathrm{N}$-alkyl aza-18-crown6 (especially dodecyl) in ILs offer not only easier recycling strategy but also better selectivity toward $\mathrm{Sr}^{2+}$.

\section{Task specific ionic liquid}

First try

TSIL for the elective liquid/liquid extraction of heavy metals from aqueous systems were first published by Rogers et alin 2001. ${ }^{[29]}$ Functionalized imidazolium cations with thioether-, urea- or thiourea-derivatized side chains act as metal ligating moieties, whereas $\mathrm{PF}_{6}$ - anions provides the desired water immiscibility. (Figure 18)

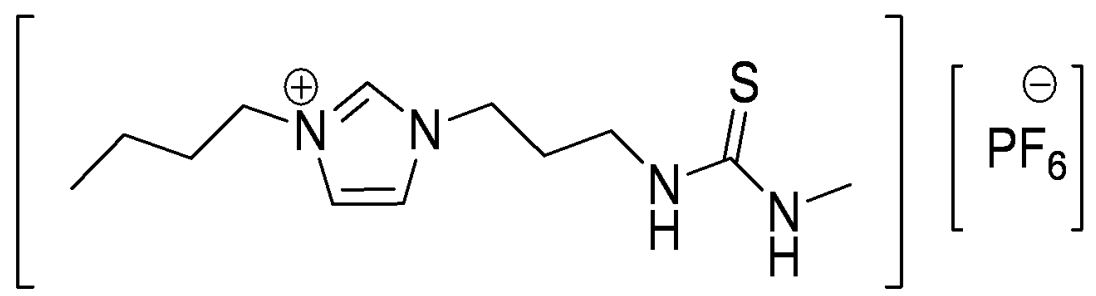

Fig. 18: Thiourea-derivatives ionic liquid

Mercury(II) and Cadmium(II) were targeted with the goal to find alternative separations strategies for removing these toxic metal ions from the environment. ${ }^{[30]}$ Those IL can be used directly as the bulk or may be doped as an extractant into less expensive IL such as $\left[\mathrm{C}_{4}\right.$ mim] $\left[\mathrm{PF}_{6}\right]$. The best ILs used are listed in the following figure:<smiles></smiles>

Fig. 19: structures of the cations combined after with $\mathrm{PF}_{6}$ 
In each case, they try to extract $\mathrm{Hg}^{2+}$ and $\mathrm{Cd}^{2+}$ directly using the $\mathrm{IL}$ and secondly by using $\left[\mathrm{C}_{4}\right.$ mim] $\left[\mathrm{PF}_{6}\right]$ with a $1: 1$ ratio and a $\mathrm{pH}$ at 1 or 7 .
This table shows that $\mathbf{1}$ is a good extractants for both mercury and cadmium and with or without $\left[\mathrm{C}_{4} \mathrm{mim}\right]\left[\mathrm{PF}_{6}\right]$. However, with the derivative

Table 4: Extraction efficiency for different composition of IL

\begin{tabular}{lllll}
\hline IL & M2- & pH (aq) & Distribution ratio & System \\
\hline 1 & $\mathrm{Hg}^{2+}$ & 1 & 200 & 1 only \\
& $\mathrm{Cd}^{2+}$ & 1 & 300 & 1 only \\
1 & $\mathrm{Hg}^{2+}$ & 1 & 170 & $1+[\mathrm{Crmim}]\left[\mathrm{PF}_{6}\right](1: 1)$ \\
& $\mathrm{Cd}^{2+}$ & 1 & 310 & $1+[\mathrm{Crmim}]\left[\mathrm{PF}_{6}\right](1: 1)$ \\
1 & $\mathrm{Hg}^{2+}$ & 1 & 210 & 1 only \\
& $\mathrm{Cd}^{2+}$ & 1 & 380 & 1 only \\
1 & $\mathrm{Hg}^{2+}$ & 1 & 210 & $1+[\mathrm{Crmim}]\left[\mathrm{PF}_{6}\right](1: 1)$ \\
& $\mathrm{Cd}^{2+}$ & 1 & 360 & $1+[\mathrm{Crmim}]\left[\mathrm{PF}_{6}\right](1: 1)$ \\
2 & $\mathrm{Hg}^{2+}$ & 1 & 350 & 2 only \\
& $\mathrm{Cd}^{2+}$ & 1 & 20 & 2 only \\
2 & $\mathrm{Hg}^{2+}$ & 1 & 74 & $2+[\mathrm{Crmim}]\left[\mathrm{PF}_{6}\right](1: 1)$ \\
& $\mathrm{Cd}^{2+}$ & 1 & 0.0086 & $2+[\mathrm{Crmim}]\left[\mathrm{PF}_{6}\right](1: 1)$ \\
2 & $\mathrm{Hg}^{2+}$ & 1 & 340 & 2 only \\
& $\mathrm{Cd}^{2+}$ & 1 & 23 & 2 only \\
2 & $\mathrm{Hg}^{2+}$ & 1 & 100 & $2+[\mathrm{Crmim}]\left[\mathrm{PF}_{6}\right](1: 1)$ \\
& $\mathrm{Cd}^{2+}$ & 1 & 0.0074 & $2+[\mathrm{Crmim}]\left[\mathrm{PF}_{6}\right](1: 1)$ \\
\hline
\end{tabular}

2 , the ratios are lower than with 1 and it's much less effective at extraction of $\mathrm{Cd}^{2+}$. Besides, 2 doesn't extract $\mathrm{Cd}^{2+}$ when it's diluted with $\left[\mathrm{C}_{4} \mathrm{mim}\right]\left[\mathrm{PF}_{6}\right]$. So, 2 is more selective than 1 what's could be a big advantage in an extraction process. The results about the superiority of 1 and 2 can be explained by the interaction between the $S$ atom in the alkyl chain, able to react with the metal. With those results, others derivatives have been made: Figure 20.<smiles>CCCCCCn1cc[n+](CCCCCNC(=O)NCCCNC(=O)NCCCn2cc[n+](CCCCn3cc[n+](CCC)c3)c2)c1</smiles>

Figure 20: structure of imidazolium derivatives 
All those IL have the same behavior as extractants for mercury and cadmium when they're mixed in equal ratio with $\left[\mathrm{C}_{4} \mathrm{mim}\right]\left[\mathrm{PF}_{6}\right]$. In general, the ratios of $\mathrm{Cd}$ are lower than observed with $\mathrm{Hg}$.

It is noticeable that both alkyl chains appear to affect the extraction ${ }^{4}$ and that the adjustment of $\mathrm{pH}$ in acidic conditions doesn't facilitate stripping of cadmium but practically doesn't affect mercury.

It appears that increasing the alkyl chain length from butyl to octyl increases the hydrophobicity of the IL which ameliorates the ratio. Besides, the hydrophobic environment may prevent the hydrolysis.

To complete this study, tests have been made with different concentration of IL in $\left[\mathrm{C}_{4} \mathrm{mim}\right]\left[\mathrm{PF}_{6}\right]$.

That kind of IL shows excellent results for extraction, but the problem is the instability of the hexafluorophosphate anion by hydrolysis producing toxic and corrosive HF or fluorides. Moreover, those ionic liquids are expensive due to the price of starting materials. Besides, we still need to find a way to strip the metal from the IL phase.

\section{TOAH}

TOAH, trioctylammonium are a new kind of ILs. TOAH (Figure 21) has they are composed of four alkyl chains on the ammonium with three octyl groups and one hydrogen.

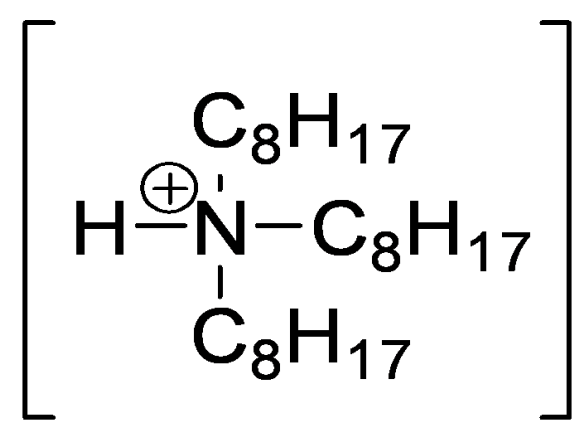

Fig. 21: TOAH

Table 5: Extraction percentage of metals with a mixture of [TOAH] $\left[\mathrm{NO}_{3}\right]$ in $[\mathrm{TOAH}]\left[\mathrm{NTf}_{2}\right]$ at $25^{\circ} \mathrm{C}$

\begin{tabular}{lcccc}
\hline $\begin{array}{l}\text { Concentraiton of } \\
\text { Hcl }\left(\mathrm{mol} \mathrm{dm}^{-3}\right)\end{array}$ & $\begin{array}{l}\mathbf{R h}(\mathrm{III}) \\
\mathbf{E}(\%)\end{array}$ & $\begin{array}{l}\mathbf{P d}(\mathrm{II}) \\
\mathbf{E}(\%)\end{array}$ & $\begin{array}{l}\mathbf{C d}(\mathrm{II}) \\
\mathbf{E}(\%)\end{array}$ & $\begin{array}{l}\mathbf{P t}(\mathrm{IV}) \\
\mathbf{E}(\%)\end{array}$ \\
\hline 0.10 & 4.6 & 99.8 & 0.5 & 92.5 \\
1.0 & 4.0 & 96.7 & 54.2 & 92.7 \\
2.0 & 4.6 & 92.6 & 67.7 & 86.7 \\
4.0 & 1.3 & 81.9 & 68.5 & 79.0 \\
\hline
\end{tabular}

A study from Katsuka et alshows excellent results for Platinum and Palladium. But the results were even better when there was two different ionic liquids of TOAH were mixed. The difference between the two ILs, was the anion. ${ }^{[31]}$

Another factor needs to be considered: the $\mathrm{pH}$. Indeed, as the TOAH is an ammonium, the acidic proton on the ammonium can be removed if the $\mathrm{pH}$ isn't acid enough. With that optic, Katsuka and co-workers have studied the power of $\mathrm{pH}$ on the extractability for several transition metals. The following table is giving results for some of them.
This table shows that for each metal, the dependency of $\mathrm{pH}$ is not the same. In fact, for $\mathrm{Pd}$, the concentration of $\mathrm{HCL}$ needs to be not too high whereas for the Cd it's the contrary. A compromise for each metal needs to be made to find the perfect process.

Concerning the back extraction of the metal from the IL, a simple stripping with nitric acid is enough for most of the metals. But some of them, like the palladium, the recycling is not so efficient or we need to provide really high concentration of $\mathrm{n}$ nitric acid. 
So, TOAH has high extractability in acidic condition than general hydrophobic ionic liquids and the major advantage is the control of the extractability by the composition of the mixture. Besides, Most of the metals extracted in the IL can be stripped through back-extraction with aqueous nitric acid solution to regenerate IL.

\section{TOMATS}

Trioctylmethylammonium thiosalicylate known as TOMATS are the better results today for the extraction of heavy metals adapted from the TOAH derivatives. The difference is the longer alkyl chain on the fourth substituent.

This is the novel high-performance, TSIL for the extraction of heavy metals from aqueous solution. To overcome the previous problems, TOMATS (Figure 22) contain no fluorine and is absolutely stable towards hydrolysis.

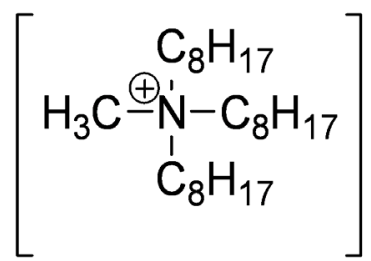<smiles>O=C([O-])c1ccccc1S</smiles>

Fig. 22: TOMATS

Table 6: The TOMATS and derivatives

\begin{tabular}{|c|c|c|c|}
\hline Name/Symbol & Structure & Name/Symbol & Structure \\
\hline Tricaprylmethyl & & Tricaprylmethyl & \\
\hline $\begin{array}{l}\text { ammoniumthiosalicylate } \\
{[\text { A336][TS] }}\end{array}$ & & $\begin{array}{l}\text { ammonium } \\
\text { 2-(methylthio) benzoate } \\
{[\text { A336][MTBA] }}\end{array}$ & \\
\hline Tricaprylmethylammonium & & & \\
\hline $\begin{array}{l}\text { benzoate } \\
{[\mathrm{A} 336][\mathrm{BA}]}\end{array}$ & & $\begin{array}{l}\text { Tricaprylmethylamm } \\
\text { onium } \\
\text { Hexanoate } \\
\text { [A336][Hex] }\end{array}$ & \\
\hline Tricaprylmethylammonium & & Trihexyl(tetradecyl) & $\begin{array}{c}\mathrm{C}_{1} \mathrm{H}_{\mathbf{3}} \\
\mathrm{C}_{\mathbf{6}} \mathrm{H}_{13} \mathrm{CM}_{\mathrm{N}}^{\mathrm{N}}-\mathrm{C}_{\mathbf{6}} \mathrm{H}_{13} \\
\mathrm{C}_{\mathbf{6}} \mathrm{H}_{13}\end{array}$ \\
\hline $\begin{array}{l}\text { Thiocyanate } \\
{[\text { A336][SCN] }}\end{array}$ & & $\begin{array}{l}\text { phosphonium 2- } \\
\text { (mercapto)Benzoate } \\
\text { [PR4][MTBA] }\end{array}$ & \\
\hline Trihexyl(tetradecyl) & & Trihexyl(tetradecyl) & $\mathrm{C}_{6} \mathrm{H}_{13}{ }_{\mathrm{C}_{6}} \mathrm{~S}_{\mathrm{E}}-\mathrm{C}_{\mathrm{B}} \mathrm{H}_{13}$ \\
\hline $\begin{array}{l}\text { Phosphonium salicylate } \\
\text { [PR4][Sal] }\end{array}$ & & \multicolumn{2}{|c|}{$\begin{array}{l}\text { phosphonium 2- } \\
\text { (methylthio)Benzoate[PR4][MTBA] }\end{array}$} \\
\hline
\end{tabular}


The efficiency of TOMATS can be explained by the chelating effect of the orthosubstituted carboxylate group relative to the thiol functionality. The bigger advantage is the facility to produce it at industrial scale. The first application is the extraction of copper from an aqueous $\mathrm{Cu}^{2+}$ tetramine phase. After the addition of TOMATS, two phases are seen: one with copper-free region and a dark copper-containing upper region. After shaking and separation of the phases, all the copper is extracted into the upper phase (third test tube). ${ }^{[32]}$

It is noticeable that sometimes separation takes quite a long time due to the high viscosity of TOMATS. This can be avoiding by the addition of immiscible organic solvent or by gentle heating of the mixture. Moreover, it can be improved by using centrifuge or adding small amount of sodium sulfate to the aqueous phase before shaking.

Most recently studies made by Hann and co-workers, used TOMATS as extraction ionic liquids from industrial water. The evaluation of the potential of anion functionalized IL as extracting agents for $\mathrm{Cd}, \mathrm{Ni}, \mathrm{Hg}, \mathrm{Pb} .$. was studied. ${ }^{[31]}$ With that intention, different TOMATS have been made, listed in the Table 6.

After 120 minutes of extraction, the ILs revealed high extraction efficiency for $\mathrm{Ag}, \mathrm{Hg}$ and $\mathrm{Pt}$, whereas only a limited fraction of $\mathrm{As}, \mathrm{Cr}$ and $\mathrm{Ni}$ could be eliminated from the solutions.

The high extractability of mercury is due to the fact that it's soluble either in functionalized or unfunctionalized ILs. The similar tendency is observed for Ag. Interestingly, $\mathrm{Cd}, \mathrm{Pb}$ and $\mathrm{Zn}$ could be partially eliminated from the model solution by $\left[\mathrm{PR}_{4}\right][\mathrm{TS}]$ but there was no effect on the corresponding ammonium cation with the same anion [A336][TS]. So, it appeared that both cation ring and anion are strongly influencing the metal extraction from water. Generally, the extraction efficiency was higher for IL with [TS], [MTBA] or [SCN] than those with [BA], [hex] or [sal] indicating that the sulphur containing functional groups strongly affect the extraction efficiency. This property was already shown with others ILs. ${ }^{[33]}$

It is noticeable that there is a correlation between the contact time of IL and metals and the extraction efficiency.

Another factor influences the extraction efficiency is the $\mathrm{pH}$. As it was demonstrated earlier, an acidic $\mathrm{pH}$ doesn't facilitate the extraction.

According to those results, TSIL TOMATSderivatives represent a good procedure for selective cleaning of contaminated waste water. In particular, thiol, thioether- functionalized are efficient for instance for communal waste cater. But, for industrial water, full of $\mathrm{Zn}$, it's recommended to use [A336][SCN]. Although those ILs are efficient, the problem still is the price of the extraction due to the price of the ILs.

That study is the following of a previous one made by Kalb et al in 2006, where they could extract heavy metals (principally mercury) from waste water using the commercially available TOMATS. ${ }^{[34]}$ They also proved that TOMATS can extract heavy metals by forming metal-thiolate and additionally a complex-bond with the carboxylate group of the thiosalicylate anion, favoring the extraction process.

The high extractability of $\mathrm{Ag} \mathrm{Hg}$ has been already demonstrated by Papaiconomou et al in 2008 with pyridines and piperidines derivatives ILs. ${ }^{[35]}$ With that intention, they synthesized several new types of lls summarized in the Figure 23.

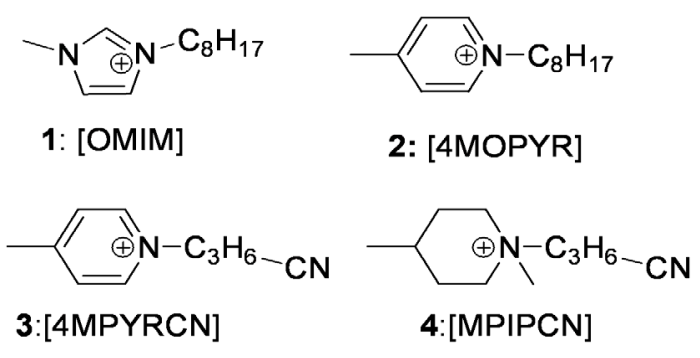

Fig. 23:

After the study of RTILs 1 , they studied the same property for the ILs 2 to 4 . The results are that except for mercury, ILs containing pyridinium cations have poor extraction activity. However, TSILS containing a nitrile functionappear to be good and selective extracting agents for silver and palladium 
ions. Finally, piperidines cations don't show any amelioration toward the extraction compared to the same with pyridinium cations.

Egorov et al. studied the extraction property of TOMATS toward Iron(III) and Copper(II). ${ }^{[36]}$ The findings were that Iron and Copper are the most stable salicylate complexes so the results of extractions were high. However, for Nickel and Manganese, the ratios were low due to their poor stability as complexes.

Finally, binary mixtures of the ionic liquid betainium bis(trifluoromethylsulfonyl) imide and water show an upper critique solution temperature ${ }^{37}$. This solvent system has been used to extract metal ions by phase-transition extraction, using zwitterionic betaine as extractant. The system is efficient for the extraction of trivalent rare-earth, indium, and gallium ions. This new type of metal extraction system avoids problems associated with the use of viscous ionic liquids.

\section{CONCLUSION}

Nowadays, rare earth elements and heavy metals are big challenges for industries both environmentally and economically with the increasing demand of rare earth elements. This work listed the different techniques used to extract them from aqueous solution with the goal to reuse those metals after their extraction in wastes.

Some promising techniques have been demonstrated like the task-specific ionic liquids for both heavy metals and rare earth elements.

Moreover, processes about the recovery of the metal from the IL extractant phases have been realized with excellent results. The only problem which remains is the price of the TSILS.

Finally, new applications are coming up for the use of IL in the recovery of nuclear wastes giving encouraging results. ${ }^{[38]}$

\section{REFERENCES}

1. Ionic Liquids Today Issue $2-11$, Monday, 19th September (2011).

2. Zuo, Y.; Liu, Y.; Chen, J.; Li, D. The separation of cerium(IV) from nitric acid solutions containing thorium(IV) and lanthanides(III) using pure [C8mim] PF6 as extracting phase. Ind. Eng. Chem. Res. 47: 2349-2355 (2008).

3. Nakashima, K.; Kubota, F.; Maruyama, T.; Goto, M. Ionic Liquids as a Novel Solvent for Lanthanide Extraction. Anal. Sci., 19: 10971098 (2003).

4. Yang, F; Kubota, F.; Kamiya, N; Goto; M. Extraction and Separation of Rare Earth Metal lons with DODGAA in lonic liquids. Solv. Extr. Res. Dev. Jpn. 19(1): 17-28 (2012).

5. Baba, Y.; Kubota, F.; Kamiya, N.; Recent Advances in Extraction and Separation of Rare-Earth Metals Using Ionic Liquids. Journal of Chemical Engineering of Japan, 44(10): 679-685 (2011).

6. Jensen, M. P.; Neuefeind, J.; Beitz, J. V.; Skanthakumar, S.;Soderholm, L. Mechanisms of Metal Ion Transfer into RoomTemperature Ionic Liquids: The Role of Anion
Exchange. J. Am. Chem. Soc., 125: 1546615473 (2003).

7. Yoon, S. J.; Lee, J. G.; Tajima, H.; Yamasaki, A.; Kiyono, F.; Nakazato, T.; Tao, H. Extraction of lanthanide ions from aqueous solution by bis(2-ethylhexyl)phosphoric acid with roomtemperature ionic liquids. J. Ind. Eng. Chem. 16: 350-354 (2010).

8. Rout, A.; Karmakar, S.; Venkatesan, K. A.; Srinivasan, T. G.; Vasudeva Rao, P. R. Room temperature ionic liquid diluent for the mutual separation of europium(III) from americium (III). Sep. Purif. Technol., 81: 109-115 (2011).

9. C. Michael and R.W. Sugumar, Orient J. Chem., 29(3): 1149-1154 (2013).

10. C. Michael and R. W. Sugumar., Orient. J. Chem., 29(3): 1149-1154 (2013).

11. Didi, M.A.; Medjahed, B.; Benaouda, W. Adsorption by Liquid-Liquid extraction of $\mathrm{Hg}$ (II) from aqueous solutions using the 2-butylimidazolium di-(2-ethylhexyl) phosphate as ionic liquid. American Journal of Analytical Chemistry, 2013, 4, ${ }^{* *}$ (in press) Published Online July 2013 (http://www.scirp.org/ 
journal/ajac).

12. Kubota, F.; Koyanagi, Y.; Nakashima, K.; Shimojo, K.; Kamiya, N.; Goto, M. Extraction of lanthanide ions with an organophosphorous extractant into ionic liquids. Solv. Extr. Res. Dev. Jpn, 15: 81-87 (2008).

13. Sun, X. Q.; Ji, Y.; Guo, L.; Chen, J.; Li, D. Q. A novel ammonium ionic liquid based extraction strategy for separating scandium from yttrium and lanthanides. Sep. Purif. Technol., 81: 25-30 (2011).

14. Liu, Y. H.; Zhu, L. L.; Sun, X. Q.; Chen, J.; Luo, F. Silica Materials Doped with Bifunctional Ionic Liquid Extractant for Yttrium Extraction. Ind. Eng. Chem. Res., 48(15): 7308-7313 (2009).

15. Mallah, M.H. ; Shemirani, F. ; Maragheh, M.G. Ionic Liquids for Simultaneous Preconcentration of Some Lanthanoids Using Dispersive Liquid"Liquid Microextraction Technique in Uranium Dioxide Powder. Environ. Sci. Technol., 1947-1951 (2009).

16. Mallah, M. H. ; Shemirani, F. ; Maragheh, M. G. ;Jamali, M. R. Evaluation of synergism in dispersive liquid-liquid microextraction for simultaneous preconcentration of some lanthanoids. J. Mol. Liq., 151: 122-124 (2010).

17. Kubota, F.; Shimobori, Y.; Baba, Y.; Koyanagi, Y.; Shimojo, K.;Kamiya, N.; Goto, M. Application of Ionic Liquids to Extraction Separation of Rare Earth Metals. J.Chem. Eng. Japan, 44: 307-312 (2011).

18. Yang, F.; Baba, Y.; Kubota, F.; Kamiya, N.;Goto, M. Extraction and Separation of Rare Earth Metal lons with DODGAA in lonic liquids. Extr. Res. Dev. Jpn, 19: 69-76 (2012).

19. Baba, Y.; Kubota, F.; Kamiya, N.; Goto, M. Selective Recovery of Dysprosium and Neodymium Ions by a Supported Liquid Membrane Based on Ionic Liquids. Solv. Extr. Res. Dev. Jpn, 18: 193-198 (2011).

20. Mehdi, H.; Binnemans, K.; Van Hecke, K.; Van Meervelt, L.; Nockemann, P. Hydrophobic ionic liquids with strongly coordinating anions. Chem. Commun., 46: 234-236 (2010).

21. Nockemann, P.; Thijs, B.; Postelmans, N.;
Van Hecke, K.; Van Meervelt, L.; Binnemans, $\mathrm{K}$. Anionic rare-earth thiocyanate complexes as building blocks for low-melting metalcontaining ionic liquids. J. Am. Chem. Soc., 128(42): 13658-13659 (2006).

22. Vicente, J.A.; Mlonka, A.; Nimal Gunaratne, H.Q.; Swadzba-Kwa[ny, M.; Nockemann, P. Phosphine oxide functionalised imidazolium ionic liquids as tuneable ligands for lanthanide complexation. Chem. Commun., 48: 6115-6117 (2012).

23. Peter Nockemann. Metals in ionic liquids:positive or negative? conference (2012)

24. Nockemann, P.; Thijs, B.; Pittois, S.; Thoen, J.; Glorieux, C.; Van Hecke, K.; Van Meervelt, L.; Kirchner, B.; Binnemans, K. Task-specific ionic liquid for solubilizing metal oxides. J. Phys. Chem. B, 110: 20978-20992 (2006).

25. Germani, R.; Mancini, M. V.; Savelli, G.; Spreti, $\mathrm{N}$. Mercury extraction by ionic liquids: temperature and alkyl chain length effect. Tetrahedron Lett., 48: 1767-1769 (2007).

26. Lertlapwasin, R.; Bhawawet, N.; Imyim, A. Fuangswasdi, Slonic liquid extraction of heavy metal ions by 2-aminothiophenol in 1-butyl-3-methylimidazolium hexafluorophosphate and their association constants. Sep. Purif. Technol., 72(1): 70-76 (2010).

27. Wei, Guor-Tzo; Yang, Zusing; Chen, ChaoJung. Room temperature ionic liquid as a novel medium for liquid/liquid extraction of metal ions. Analytica Chimica Acta, 488(2): 183-192 (2003).

28. A. Yazolani and Mona Akbari., Orient. J. Chem., 28(3): 1219-1227 (2012).

29. Huimin,L.; Sheng,D.; Bonnesen, P.V. Solvent Extraction of Sr2+ and Cs+ Based on RoomTemperature Ionic Liquids Containing Monoaza-Substituted Crown Ethers. Analytical Chemistry, 76(10): 2773-2779 (2004).

30. Visser, A. E.; Swatloski, R. P.; Reichert, W. M.; Mayton, R.; Sheff, S.; Wierzbicki, A.; Davis, Jr. J. H.; Rogers, R. D. Task-specific ionic liquids for the extraction of metal ions from aqueous solutions. Chem. Commun. 135-136 (2001).

31. Visser, A. E.; Swatloski, R. P.; Reichert, W. M.; Mayton, R.; Sheff, S.; Wierzbicki, A.; Davis, J. H., Jr.; Rogers, R. D. Task Specific Ionic 
Liquids Incorporating Novel Cations for the Coordination and Extraction of $\mathrm{Hg} \mathrm{2}+$ and $\mathrm{Cd} 2+$ : Synthesis, Characterization and Extraction Studies. Environ. Sci. Technol. 36: 2523-2529 (2002).

32. Katsuta, S.; Yoshimoto, Y.; Okai, M.; Takeda, Y.; Bessho, K. Selective Extraction of Palladium and Platinum from Hydrochloric Acid Solutions by Trioctylammonium-Based Mixed Ionic Liquids. Ind. Eng. Chem. Res., 50(22): 12735-12740 (2011).

33. Ionic Liquids Chem Files 6(9): (2006).

34. Fischer, L.; Falta, T.; Koellensperger, G.; Stojanovic, A.; Kogelnig, D.; Galanski, M.; Krachler, R.;Keppler, B.K., Hann, S. Ionic liquids for extraction of metals and metal containing compounds from communal and industrial waste water. Water Research 45(15): 4601-4614 (2011).

35. Kalb, R.S.; Krachler, R.; Keppler, B.K.; In: Ho" flinger, W. (Ed.), Chemical Industry and Environment V, 2006, vol. I, Vienna, Austria.

36. Papaiconomou, N.; Lee, J.M.; Salminen, J.;
Von Stosch, M.; Prausnitz, J.M. Selective Extraction of Copper, Mercury, Silver, and Palladium Ions from Water Using Hydrophobic lonic Liquids. I. Ind. Eng. Chem. Res. 47: 5080-5086 (2008).

37. Egorov, V.M.; Djigailo, D.I.; Momotenko, D.S.; Chernyshov, D.V.; Torocheshnikova, I.I.; Smirnova, S.V.; Pletnev, I.V. Task-specific ionic liquid trioctylmethylammonium salicylate as extraction solvent for transition metal ions. Talanta, 80: 1177-1182 (2010).

38. Hoogerstraete, T.V.; Onghena, B.; Binnemans, K.; Homogeneous Liquid-Liquid Extraction of Metal Ions with a Functionalized Ionic liquid. Journal of Physical Chemistry Letters, 4(10): 1659-1663 (2013).

39. Nockemann, P.; Servaes, K.; Van Deun, R.; Van Hecke, K.; Van Meervelt, L.; Binnemans, K.; Görller-Walrand, C. Speciation of Uranyl Complexes in Ionic Liquids by Optical Spectroscopy. Inorganic Chemistry, 46(26): 11335-11344 (2007). 